\title{
Laboreal
}

Volume 15 N$^{\circ} 2$ | 2019

Varia

\section{Adaptação da Máquina ao Homem}

Adaptación de la máquina al hombre

Adaptation de la machine à l'homme

Adaptation of Machine to Man

\section{Jacques Leplat}

Tradutor. João Viana Jorge

\section{OpenEdition}

\section{Journals}

\section{Edição electrónica}

URL: http://journals.openedition.org/laboreal/14922

DOI: 10.4000/laboreal.14922

ISSN: 1646-5237

\section{Editora}

Universidade do Porto

\section{Refêrencia eletrónica}

Jacques Leplat, "Adaptação da Máquina ao Homem », Laboreal [Online], Volume 15 №2 | 2019, posto online no dia 01 dezembro 2019, consultado o 23 setembro 2020. URL : http://

journals.openedition.org/laboreal/14922 ; DOI : https://doi.org/10.4000/laboreal.14922

Este documento foi criado de forma automática no dia 23 setembro 2020.

\section{c) (7) (8)}

Laboreal está licenciado com uma Licença Creative Commons - Atribuição-NãoComercial 4.0 Internacional. 


\title{
Adaptação da Máquina ao Homem
}

\author{
Adaptación de la máquina al hombre \\ Adaptation de la machine à l'homme \\ Adaptation of Machine to Man
}

Jacques Leplat

Tradução : João Viana Jorge

\section{REFERÊNCIA}

Texto original : Leplat, J. (1953). Adaptation de la machine à l'homme. Bulletin du Centre d'études et recherches psychotechniques, 2(1), pp. 35-39.

1 A psicologia industrial americana viu, nestes últimos anos, o desenvolvimento de todo um corpo de pesquisas geralmente agrupadas sob o nome de «Human Engineering». Não é evidentemente intenção nossa julgar aqui o que será, para a América, o significado económico e social desses esforços; a nossa finalidade é fornecer uma visão de conjunto dos trabalhos que suscitou e de mostrar o interesse que estes apresentam para nós.

2 Em primeiro lugar é necessário definir esta nova e complexa disciplina. A tradução de «Human Engineering» é difícil. Traduzindo os sinónimos americanos obter-se-ia «biomecânica, psicofísica aplicada, psicotecnologia, psicologia da mecanização». Foi frequentemente proposto em França «Adaptação da máquina ao homem». Esta expressão, se não é plenamente satisfatória tem pelo menos a vantagem de ser simples, o que nos fez adoptá-la. Se se tivesse pretendido dar um título a esse novo ramo da psicologia que desseconta, simultaneamente do seu método e do seu objeto, teria sido necessário escolher «psicologia experimental aplicada» (Chapanis 1-2) precisando «às relações do homem e da máquina». Mas, melhor que uma definição, a análise das origens da «Human Engineering» permite-nos apreender os seus princípios e domínio. Situa-se na confluência de três ordens de pesquisas (1): o estudo dos tempos e movimentos, a seleção e a psicologia experimental. 
Os engenheiros de tempos e movimentos foram os primeiros a debruçar-se de um modo algo sistemática sobre as relações do homem e da máquina. Os estudos de movimentos, por exemplo, dos quais os Gilbreth foram os iniciadores são consagrados à análise dos gestos e à descoberta dos mais económicos. $\mathrm{Na}$ medida em que estes estudos conduziram à reorganização das máquinas, das ferramentas, dos locais e das condições de trabalho, pode dizer-se que eles se enquadravam já na «Adaptação da máquina ao homem».

4 A seleção constitui uma outra abordagem dos problemas profissionais. Parte daquela constatação de que os homens não eram igualmente bem sucedidos em todas as tarefas. Deve ser possível encontrar, para cada uma delas, os sujeitos mais capazes de as levar a cabo: conhecendo o homem e o trabalho tenta-se pois, o seu melhor «emparelhamento». A perspetiva na qual se coloca o «Human Engineering» é totalmente diferente. $O$ que lhe interessa não é a escolha de um indivíduo para um dado trabalho, mas a organização desse trabalho de tal modo que o maior número possível de indivíduos seja capaz de o executar. Esta distinção é importante para bem compreender o «Human Engineering». Mas ainda que visando outras finalidades a seleção tinha, contudo, preparado a via para a nova disciplina na medida em que tinha suscitado estudos de postos de trabalho e de tarefas.

5 A psicologia experimental, apesar de um passado já longo, não tinha saído até há pouco do laboratório, o que não tinha deixado de limitar-lhe o alcance das suas descobertas. Por outro lado, parecia que o estudo do trabalho, para progredir, deveria fazer apelo à experimentação. $\mathrm{Na}$ América, este encontro da psicologia experimental com os problemas do trabalho teve lugar nomeadamente no decurso da última guerra. Obrigados a sair do seu laboratório, os experimentalistas tomaram contacto com os engenheiros de tempos e movimentos e com os psicólogos encarregados da seleção. Colocados perante problemas relativos à utilização de aparelhagens complicadas procuraram a solução nos estudos experimentais. A complexidade de certos dispositivos modernos, como as cabines de aviões, mostrava que o limite das possibilidades humanas estava atingido. As medidas de seleção tornadas ineficazes, era preciso repensar a afinação dos aparelhos. Tal não podia fazer-se senão a partir de princípios que somente a experiência permitiria extrair. Assim nasceu a «Human Engineering» que viria a ganhar cada vez maior importância por via das grandes empresas.

6 Entre os diversos aspetos deste novo ramo da psicologia industrial reteremos os que mais se relacionam com as questões psicotécnicas que nos preocupam. No trabalho em geral combinam-se aspetos preceptivos e motores. É assim que, para cumprir uma dada operação é necessário dispor de um certo número de informações (perceções) a partir das quais a sucessão dos gestos adequados possa ser executada (motricidade). Pensemos no trabalho com uma máquina: somos levados a aí distinguir, de um modo algo esquemático as operações de controlo e as operações de comando; as operações de controlo consistem em reconhecer todos os indicadores visuais, auditivos, diretos ou fornecidos por instrumentos que dirigirão as operações subsequentes (operações de comando) que levarão à peça acabada. Serão também dois os grandes grupos de pesquisas da «Adaptação da máquina ao homem»: o estudo dos dispositivos de controlo e o estudo dos comandos.

7 A primeira apresenta frequentemente à partida um aspeto fisiológico. Quando se faz apelo à perceção é necessário de facto conhecer os mecanismos sensoriais que a 
condicionam para saber em que circunstâncias estes últimos são mais eficazes. Assim sendo, tendo que decidir qual a cor dos sinais luminosos utilizados durante a noite será bom dispor de informações sobre a visão noturna das cores em geral: somente depois, e a partir desses dados, se poderão experimentar diferentes tipos de sinais. Vê-se, portanto, como dados de ordem fisiológica e aparentemente teóricos vêm a imbricar-se com o estudo do trabalho.

Numerosas pesquisas da «Adaptação da máqina ao homem» relevam desse domínio dos sinais. Se se recordar que esses estudos tiveram primitivamente por objeto o melhoramento das cabines de comando dos aviões compreender-se-á a importância dos trabalhos relativos à legibilidade dos mostradores $(1,3)$. Estas pesquisas são particularmente interessantes, tanto pelo método seguido como pelos resultados obtidos. Fitts e Jones por exemplo fazem primeiro um inquérito junto dos pilotos para saber quais são os erros cometidos na leitura dos quadrantes de bordo. Tentam em seguida classificar esses erros sob um certo número de rubricas (confusão das agulhas de um mesmo quadrante, confusão das graduações, quadrante tomado por um outro, etc.). A partir dessas indicações podem então imaginar um certo número de experimentações. Foi assim que foi estudada a influência, na boa leitura, da forma dos quadrantes, da escala utilizada, do número de referências de cada escala, do sentido de rotação das agulhas, do arranjo do conjunto dos quadrantes, etc.... Nos dispositivos relativos à visão sempre os psicólogos da "Human Engineering» pesquisaram se as informações deviam ser fornecidas de preferência num gráfico ou numa tabela, tentaram descobrir o melhor tipo de esquema, os caracteres tipográficos mais legíveis em determinadas condições. No domínio auditivo devem assinalar-se os trabalhos relativos ao "mascarar (do som)", importantes para as rádio comunicações. Muitas dessas pesquisas não alcançaram ainda conclusões definitivas, todavia iluminam um pouco um domínio mantido bem obscuro até ao presente.

o proveito que podemos retirar de estudos orientados nesse sentido aparece de modo mais evidente num artigo de Gibbs (5), consagrado aos indicadores de translação das máquinas ferramenta. Sabe-se que o chariot [1] é comandado por duas manivelas munidas de um tambor graduado. Quem tenha utilizado um torno não deixou, sem dúvida, de notar as dificuldades que apresenta a utilização correta desses tambores. Uma destas é devida ao facto de que após uma volta completa da manivela o tambor volta à graduação inicial. Consequentemente, quando se tem de deslocar o chariot ao longo de uma certa distância e se pretende voltar a atacar a peça no mesmo sítio não se pode confiar apenas nas indicações do tambor senão arrisca-se errar num número inteiro de voltas. Em certos casos esta insuficiência obriga à utilização de instrumentos de medida externos (ao torno), (paquímetro ou craveira ou "péclisse", - corruptela de pied à coulisse - palmer ou parafuso micrométrico) ou a proceder a alguns cálculos, tudo operações que ocasionam perdas de tempo. Gibbs estuda experimentalmente este problema comparando o dispositivo clássico a novos sistemas. Apesar do reduzido número de sujeitos este estudo é extremamente interessante: faz apelo a profissionais, a aprendizes e a estudantes, o que permite comparações mais ricas. Mostra também todos os benefícios que podem ser extraídos de um estudo do trabalho conduzido até à experimentação.

10 Depois de ter examinado o que se refere ao modo de obter informações da máquina vejamos o outro capítulo importante de «Human Engineering» que diz respeito à utilização da máquina, quer dizer as operações que devem ser executadas uma vez 
recolhidas as informações necessárias. Esta questão pode ser encarada de dois modos diferentes conforme se parte do homem ou da máquina. No primeiro caso pergunta-se: «quais são os movimentos que o homem pode fazer? Como os faz? Como deve executálos para que sejam económicos e eficazes?». No segundo caso examinar-se-á em primeiro lugar: «Como classificar os diferentes tipos de comandos? Como utilizá-los? Como escolhê-los?». Nenhum destes pontos de vista é suficiente por si só e devem completar-se.

11 Como não se trata aqui de produzir uma classificação detalhada do que se fez neste domínio pretendemos apenas expor dois tipos de pesquisas assaz características. Sabese que numerosas tarefas exigem que se manejem aparelhos de comando sem olhar porque no mesmo momento, por exemplo, é preciso vigiar as indicações de um contador. Se diversos comandos se encontram numa mesma vizinhança há, pois, o perigo de confusão; como evitá-lo? Na pilotagem dos aviões este problema de discriminação de posições coloca-se de forma imperiosa. Fitts idealizou colocar numa sala com a forma de uma cabine de avião um certo número de alvos, análogos aos do tiro, a diferentes alturas. Cada um correspondia a uma letra de um código que o piloto aprendia previamente, este último era a seguir equipado com um par de óculos opacos e tinha de localizar o ponto central destes alvos. Para cada posição dos alvos podia, portanto, ver-se a importância e a localização dos erros. Era assim possível apreciar as diferenças de posição percebidas para uma dada colocação do operador. Ulteriormente, estas observações permitiam saber a que distância uns dos outros deviam estar os diferentes comandos conforme a sua posição em relação ao operador para reduzir ao mínimo os riscos de confusão.

12 Um segundo tipo de trabalhos que é objeto de uma literatura já importante tem ligações ao estudo dos movimentos de ajustamento com a ajuda de experiências de localização (tracking) $(1,4,6)$. Sabe-se que numerosas tarefas exigem tais movimentos $\mathrm{e}$ daí o interesse dirigido a essas pesquisas. Essas experiências consistem geralmente, para o sujeito, em fixar um objeto que se move de maneira imprevisível dentro de certos limites ou ainda a seguir esse objeto. É assim que num quadrante uma agulha se desloca de uma determinada maneira, mas desconhecida do sujeito. Uma outra agulha, esta comandada pelo sujeito deve seguir com tanta precisão quanto possível, os movimentos da primeira. Esta segunda agulha é comandada por um volante ou um botão. Um sistema de registo fornece graficamente a cada instante a posição das duas agulhas. As experiências deste tipo permitem estudar numeroso fatores (natureza dos estímulos, padrão dos estímulos, lugar relativo do comando e do estímulo, por exemplo) dos quais é necessário conhecer a importância quando se pretende organizar tarefas desta natureza.

13 Outras pesquisas puseram em relevo o interesse que havia em ter em conta movimentos dominantes, quer dizer movimentos executados naturalmente pelo sujeito quando nenhuma indicação lhe tenha sido dada. Mostrou-se também nos estudos sobre o realismo dos comandos, que não era indiferente numa dada situação que tal botão ou alavanca se movesse num dado sentido.

14 Estes são alguns tipos de pesquisas do quadro da «Human Engineering». Esta revisão está longe de ser exaustiva porque importava mais aqui dar uma ideia das pesquisas do que enumerá-las todas. Podem extrair-se destes diferentes trabalhos os elementos de um método do qual vamos tentar tornar mais precisos alguns aspetos. $\mathrm{Na}$ origem encontramos quase sempre um estudo muito minucioso do trabalho: condução por 
procedimentos variados, observação, questionário, análise dos erros, etc., permitindo extrair um certo número de fatores e emitir hipóteses. É então que se faz apelo à experimentação; e esta não mais é um exercício gratuito sendo um fim em si mesma, mas constituindo uma fase importante do processo de estudo do trabalho. É a este nível da investigação que podem ser usados os métodos estatísticos quer se trate de pensar a experimentação, de a organizar num esquema que torne a sua exploração fácil e frutuosa, quer ainda que se trate de verificar as hipóteses formuladas. Os métodos de análise da variância encontram aí uma boa aplicação. Permitem nomeadamente testar o significado dos diferentes fatores e das suas interações. Todavia o que parece característico dos estudos de «Human Engineering» é que eles geralmente não se detêm na determinação da influência dos fatores, mas tentam descobrir para cada um o seu valor ótimo. É assim que no estudo dos movimentos rotativos, por exemplo, não só se pesquisa a influência do raio (de rotação) da manivela no número de voltas por minuto que o sujeito pode executar mas também, nas mesmas condições, qual é o raio que permitirá o maior número de voltas. Nos estudos do espaçamento (dos traços) de referências num quadrante pesquisar-se-á do mesmo modo a distância entre as referências e depois a distância ótima, quer dizer aquela que reduz ao mínimo o número de erros (1). Parece ser, esta pesquisa das otimizações, característica da «Adaptação da máquina ao homem»: é por aí que ela se distingue da perspetiva da seleção. Para esta última importa antes de tudo pôr em evidência a influência dos fatores intervenientes no sistema homem-máquina. Os psicólogos da «Human Engineering» vão mais longe dado que tentam repensar a organização desse sistema e de o estabelecer em bases mais racionais. Se é bem evidente que os problemas do trabalho industrial não se podem reduzir unicamente aos problemas de utilização de máquinas não é menos verdadeiro que tais estudos podem acarretar elementos interessantes para uma organização mais humana do trabalho: vislumbra-se em particular todo o interesse que apresentam na adaptação de postos de trabalho a sujeitos deficientes. Este apanhado da «Human Engineering» é forçosamente incompleto em virtude da perspetiva adotada e do enquadramento deste artigo. Terá talvez sido suficiente para mostrar que é uma ciência jovem que ainda não explorou senão domínios limitados e cujas descobertas mantêm frequentemente um aspeto fragmentário. Os iniciadores estão disso conscientes e não deixam de sublinhar os progressos por alcançar antes de atingir uma síntese mais ou menos geral. Desde já, todavia, resultados válidos foram adquiridos e um método de pesquisa tomou forma. Quanto a nós, ainda que não nos seja evidentemente possível colocarmo-nos na perspetiva da «Human Engineering», podemos tirar desde já o maior proveito dos seus trabalhos e métodos. Fornece-nos os meios de chegar a um melhor conhecimento das tarefas industriais para as quais temos de selecionar candidatos. Além disso a introdução da experimentação no estudo do trabalho, domínio em que o empirismo foi por longo tempo a única regra, permitirá sem dúvida alcançar importantes progressos tanto no plano puramente técnico (melhoramento do material) e pedagógico (aprendizagem mais racional da tarefa) como no plano mais estritamente psicológico (orientação e seleção). 


\section{BIBLIOGRAFIA}

Só mencionamos aqui os artigos mais recente e mais importantes. Para uma bibliografia mais completa reportar-nos-emos ao livro de Chapanis e ao final dos artigos citados.

Obra completa

A. Chapanis, W. R. Garner, C. T. Morgan: Applied experimental psychology. Uma das raras obras que faz o ponto da situação das pesquisas sobre a «Human Engineering». Bibliografia abundante sobre todas as questões.

Artigos

A. Chapanis: Applied experimental psychology (Personnel psychology. Vo.5. nº1, Spring 1952.

Fitts: Psychological research on equipement in the A. A. F.

Fitts and Simon: Some relations between stimulus patterns and performance in a continuous dual pursuit task (Jounal of experimental psychology, June 1952).

C. B. Gibbs: A new indicator of machine tool travel (Occupational psychology, october 1952).

E. C. Poulton: Perceptual anticipation in tracking with two-pointer and one-pointer displays (British jornal of psychology, August 1952).

Dimensional analysis of motion (Journal of applied psychology) :

Effects of laterality and movement direction (Davis, Wehrkamp, Smith) - Oct. 1951.

Travel-distance effects (Wehrkamp and Smith) - June 1952.

Complexity of movement pattern (Rubin, Treba, Smith) - August 1952.

Transfer effects and direction of movements (Treba, Smith) - Oct. 1952.

Resumos de artigos relativos ao «Human Engineering»:

Année psychologique : Certas rubricas no interior da parte «Psychologie appliquée» são reservadas à Adaptação do máquina ao homem. Cf. No número de 1949, 93: Lecture d'instruments ; 94 : Lisibilité de texts.

Annual Review of Psychology. No capítulo «Industrial psychology», redigido por Brown et Ghiselli, um parágrafo é reservado aos trabalhos relativos à «Human Engineering».

\section{NOTAS}

1. Nota do Tradutor: Chariot - carrinho porta ferramenta que se desloca ao longo do torno, referido em muitos sítios pelo nome francês. 